\title{
Mindfulness in organizations (part 1): a critical literature review
}

Article

Accepted Version

Passmore, J. (2019) Mindfulness in organizations (part 1): a critical literature review. Industrial \& Commerical Training, 51 (2). pp. 104-113. ISSN 0019-7858 doi:

https://doi.org/10.1108/ICT-07-2018-0063 Available at https://centaur.reading.ac.uk/81824/

It is advisable to refer to the publisher's version if you intend to cite from the work. See Guidance on citing.

To link to this article DOI: http://dx.doi.org/10.1108/ICT-07-2018-0063

Publisher: Emerald

All outputs in CentAUR are protected by Intellectual Property Rights law, including copyright law. Copyright and IPR is retained by the creators or other copyright holders. Terms and conditions for use of this material are defined in the End User Agreement.

\section{www.reading.ac.uk/centaur}

\section{CentAUR}

Central Archive at the University of Reading

Reading's research outputs online 


\title{
Mindfulness in organizations (Part 1): A critical literature review
}

Jonathan Passmore

Henley Centre for Coaching, Henley Business School, University of Reading

\begin{abstract}
Purpose: This paper explores the growing science and application of mindfulness as an intervention within organizations.

Approach: This is the first in a pair of papers exploring the science and application of mindfulness in organizations. The first section of the paper provides a brief review of the research into mindfulness and its perceived benefits from a health perspective. In the second section we consider the neurobiological mechanisms behind mindfulness meditation, before finally considering the organizational research and the limitations of mindfulness at work research.
\end{abstract}

Findings: The paper notes that while there has been considerable research into health outcomes, organizational mindfulness research is still developing a comprehensive case for the wide scale application of mindfulness.

Practical implications: The paper calls for greater research into organizational mindfulness interventions through collaborations between organizations and consultants.

Originality: The paper provides a starting point for trainers and organizational development professionals to take stock and consider how mindfulness can be employed as a tool for the benefit of organizations.

Key words: Mindfulness at work, stress reduction, meditation, wellbeing, mindfulness training.

Paper type: Literature review 


\section{Introduction}

Organizations today are confronted by challenges brought by globalization, growing cultural differences in their workforce, enhanced connectivity as a result of social media and the web, and a constant drive for efficacy and efficiency, partly as a result of quarterly reporting and a desire to contain the cost of government and public services. These and other factors contribute to pressures on organisations and individuals to be 'always-on'; constantly engaging, tweeting, blogging and posting, while working with colleagues who may speak different languages, operate to different cultural norms and work in different time zones. The same managers working with these pressures are expected to operate locally, in day-to-day interactions with their teams, while simultaneously thinking strategically about the future development of their product or teams. Given all of this, it is no wonder that individuals report working life is stressful, and that focusing on a single task is challenging.

The impact of this 'always on' culture has been higher levels stress and fatigue, leading to higher absenteeism. In a survey of US employees, $25 \%$ reported that they 'felt the need to scream or shout as a result of workplace stress', while the authors of the report estimated that $\$ 300$ billion is lost each year as a result of workplace absenteeism (AIS, 2016). The situation is no different in the European Union, where 147 million workers report having to work 'at high speed and to tight deadlines' (AIS, 2016). In the UK the number of sick days lost to stress, depression and anxiety has increased by $24 \%$ since 2009 and the number lost to serious mental illness has doubled. While the data is unavailable for Africa and Asia's economies, an assumption could be made that cost pressures from developed world global companies and lack of local labour laws are likely to have similar effects on workers in these economies.

In this paper we aim to explore how mindfulness can offer a positive tool to help individuals and organisations enhance their resilience and thus better cope with stress and contribute to enhanced workplace performance and wellbeing through a review of organisational mindfulness literature. Our focus is applied rather than theoretical and our aim is to help managers, as well as consultants to develop a deeper understanding of the potential of mindfulness in organisations, without being overcome by the hype that has been present in some practitioners' magazines.

\section{What is mindfulness?}

The term mindfulness is derived from a translation of the term 'Sati'. Sati combines aspects of 'awareness', 'attention' and 'remembering', which are conducted with non-judgement, acceptance, kindness and friendliness to oneself and others.

A number of writers have offered definitions of mindfulness over the two thousand five hundred years of its history. Bhikkhu suggests that at its most simple 
mindfulness can be considered to be 'reflective awareness' (Bhikkhu, 1998, p47). Chaskalson suggests it is 'the quality of awareness that comes from paying attention to yourself, others and the world around you' (Chaskalson, 2014, p6), while KabatZinn suggests it is a way of paying attention on purpose in the present moment and non-judgmentally :"Mindfulness is simply a practical way to be more in touch with the fullness of your being through a systematic process of self-observation, selfinquiry and mindful action. There is nothing cold, analytical or unfeeling about it. The overall tenor of mindfulness practices gentle, appreciative, and nurturing" (KabatZinn, 1991, p13).

While some attempts have been made to build an operational definition (Bishop et al., 2004) there remains a lack of an agreed definition that makes the area of research into mindfulness fraught with difficulty (Lutz et al., 2015). It is however not our objective in this paper to focus on definitions and the differences between researchers as to the nature and scope of mindfulness. What can be concluded from a review of the literature is the growth in the number of published papers, which have blossomed since 2010.

\section{Flow, Mindlessness and mindfulness}

Most of us, at one-time or another, have experienced being so deeply engaged in an activity that we lose the perception of time. It happens to me when writing. It can happen to others when they are rock climbing, teaching or playing sport. In these moments we become absorbed and fully focused, engaged in the task, with no awareness of passing time or other distractions. This state, known as Flow, has been defined as:

"a state in which people are so involved in an activity that nothing else seems to matter; the experience is so enjoyable that people will continue to do it even at great cost, for the sheer sake of doing it." (Cskikszentmihalyi, 1990, p.4)

These moments of complete absorption however are rare and possibly the most common state individuals find themselves in is that of 'mindlessness' (Smallwood \& Schooler, 2006). We can all recall a time when we forgot the name of someone who had just been introduced to us at work. Or perhaps once, when on our way home from work, we needed to buy milk, but found ourselves at home, having forgotten to go to the shop.

For many, this lack of focus on the present impacts on the quality of relationships with co-workers, it can amplify the stress as a result of constant rumination about past events, or contribute to increased anxiety over future events. In each case the wandering mind impacts on our ability to complete the task in hand, by either reducing the speed which we complete the task at, or leading to errors in task performance. 
Mindfulness has similarities with flow. When our mind is engaged in a flow state we are fully engaged, but is goal directed. In mindfulness our attention is directed to experiencing each and every moment to the full, accepting each, without questioning or judging.

Dust (2015) has suggested that both mindfulness and flow states offer benefits. The selection of one as opposed to the other depends on the nature of the task involved. Flow may suit tasks requiring a narrow attention breadth, such as writing, while a wider attentional breadth of mindfulness may suit other tasks, example might include security or safety workers, where a wider situational awareness may help identity and thus manage potential risks in the environment.

\section{Method}

For this review we undertook a literature review of published peer-reviewed research using the 'ARC One-Search'. This tool reviews all the main business databases in a single search including EBSCO, Emerald Insight, Business Source Complete, Science Direct and British Library EThOS. The initial search was for the period 1934-2018 using the term 'Mindfulness'. This revealed a total of 18,141 peer review papers. A second review of the terms 'Mindfulness' and 'Work' for the same period revealed a total of 10,369 papers. What was interesting was that by shortening the timeframe from 2000-2018 this only lead to a small reduction to 9,939. A further focusing to the time frame of 2010-2018 led to the inclusion of 8,463 . A revised series of terms was then used 'Mindfulness' and 'Organisations'. For the period 2010-2018 this lead to a total of 608 papers being identified. Rather than adopt a systematic review covering all papers within the review, our aim in this paper is to provide insights drawn from this literature to assist practitioners in their understanding of the literature and how mindfulness can contribute towards improvements in organizational policy and practice for wellbeing and performance.

\section{The science of mindfulness}

Over the past three decades research has begun to reveal the benefits of using mindfulness, and these findings have coincided with a growth in the number of published papers exploring both the science and application of mindfulness. As noted in the sheer numbers of literature of mindfulness at work has thus exploded within the ten years.

A brief review of any paper from the wealth of published material confirms that mindfulness is a useful ally in efforts to improve physical and psychological wellbeing. While a review of the wider literature reveals that most early studies focused on health care, there are a growing number of organizational studies. In the following section we will start by reviewing the health and wellbeing research, before turning to consider the research relating to workplace performance, and the opportunities to apply these research findings through organizational interventions. 


\section{Health \& wellbeing research}

Over the two decades the research literature on the benefits of mindfulness has proliferated, with multiple physical and psychological benefits being associated with higher levels of mindfulness.

A number of studies have been conducted in to physical health from cancer care, to heart disease, pain management and blood pressure. In a meta-analysis of this work by Cramer (2012), the researchers examined the results from a series of breast cancer randomized control trials, comparing mindfulness interventions with different comparable interventions. The results revealed preliminary signs that mindfulness could be more effective than other interventions including 'treatment as normal', 'nutrition education' and 'free choice stress management'. Similar finding has been confirmed in heart disease. In a single randomised control trial of 30 male heart disease patients, half the patients were allocated to an eight week Mindfulness-Based Stress Reduction program, while half received treatment as normal. A significant reduction was observed in anxiety and depression, perceived stress, blood pressure and BMI in patients of the MBSR group after the completion of intervention assessment. At the 3-month follow-up, therapeutic gains were maintained in patients of the MBSR group (Parswarni et al., 2013). Mindfulness has also been shown to positively impact the ability of patients to manage pain. Jong et al. (2016) explored body awareness and the effect of mindfulness in managing chronic pain. Using a variety of scales the team measured the impact of mindfulness training on pain when compared with treatment as normal intervention for pain management. The results provide preliminary evidence of the power of mindfulness in helping pain sufferers manage chronic pain. While at a more general level, research by McCraty (2003) and Rein \& McCraty (1995), examining the impact of mindfulness on the immune system has shown that mindfulness meditation has a positive impact on physical health including reducing blood pressure levels and enhancing the immune system to fight off infection. Over a three-month post intervention period they noted the mindfulness group saw a reduction of $10.6 \mathrm{~mm}$ $\mathrm{Hg}$ in systolic and $6.3 \mathrm{~mm} \mathrm{HG}$ in diastolic Blood pressure, these reductions in blood pressure levels were significant when compared with the control group.

A second area of direct benefit is the area of wellbeing, including the positive effects of mindfulness for mental health, depression and trauma. Previous research has already demonstrated the association between excessive rumination and negative effect (Thomsen, 2004). In a study by Chambers et al. (2008) the researchers asked 20 novice meditators to participate in a 10-day intensive mindfulness meditation retreat. After the retreat, the meditation group had significantly higher self-reported mindfulness and a decreased negative affect, compared with a control group. They also experienced fewer depressive symptoms and less rumination. Mindfulness practice has also been shown to have a positive impact on protecting individuals who may be exposed to trauma, such as emergency services personnel and those in the armed forces. In a study examining the effects of emotionally distressing images and colleagues found that individuals who regularly practices mindfulness were more effective at disengage from the emotionally upsetting images and were better

Passmore, J. (2018). Mindfulness at organisations: A critical literature review. Industrial \& 5 Commercial Training. DOI: 10.1108/ICT-07-2018-0063 
able to focus on a cognitive task, when compared with participants who saw the pictures, but did not meditate (Ortner et al., 2007). Similar positive impacts have also been shown in terms of improving mood, reducing anxiety and stimulating a positive emotional affect. A meta-analysis by Hoffman et al. (2010) of 39 studies concluded that mindfulness was useful in altering affective and cognitive processes, with a moderate effect size for improving anxiety (Hedge's g=0.63) and improving $\operatorname{mood}(g=0.59)$.

Research has also shown mindfulness to have positive effects on general brain performance including working memory and cognitive attention, specifically stability (Smallwood \& Schooler, 2015), control (Ocasio, 2011) and efficiency (Neubauer \& Fink, 2009). In a study with participants from the armed forces, Jha, et al. (2010) found that participating in mindfulness based practice had a positive effect on preserving working memory function during periods of stress, and resulted in higher levels of self reported positive affect (indexed by the PANAS). Moore and Malinowski (2009) looked at the impact of mindfulness on cognitive attention. They found that the meditation group had significantly better performance on all measures of attention and had higher self-reported mindfulness and that these factors were positively correlated directly with cognitive flexibility and attentional functioning.

Finally looking at the interpersonal level, work by Barnes et al. (2007) found that mindfulness contributed towards an individual's ability to respond well to relationship stress and had a positive effect in communicating one's emotions to others. Other studies have confirmed similar findings with mindfulness practitioners displaying improved ability to express oneself in various social situations and with higher levels of mindfulness practice a predictor relationship satisfaction (Dekeyser et al., 2008; Wachs \& Cordova, 2007).

\section{Neurobiological research}

Alongside the health and wellbeing benefits researchers have been examining the neurological effects of mindfulness practice on the human brain. These research studies reveal that mindfulness practice is associated with physical changes to the brain structure in regions associated with the development of attention, short-term memory and executive functioning, and in addition, appears to result in the reduction of cognitive decline associated with aging of the brain.

In a study by Creswell (Creswell et al., 2016) the team explored the impact of mindfulness training on the default mode network (DMN). Using a randomized controlled trial of 35 participants, who were unemployed job seekers, the team found mindfulness produced positive effects when compared to relaxation training and these effects continued to be observed in a 4-month follow-up.

Research by Taren, Creswell and Gianaros (2013) explored the impact of mindfulness interventions on grey matter. The researchers scanned the brains of 155 healthy adults using structural $\mathrm{fMRI}$ images. An analysis of these images showed that higher dispositional mindfulness is associated with decreased grey matter volume in the 
right amygdala, and decreased grey matter volume in the left caudate. These differences persisted when controlled for demographic and individual factors, including age, total grey matter volume, neuroticism and depression. The researchers suggested that these physical differences in grey matter may explain why mindful individuals have reduced stress reactivity.

Finally, work by Singleton and his colleagues (Singleton et al., 2014) has show interesting results in gray matter which has been found to increase in several brain areas, including areas involved with physiological response to stress and panic. These increases resulted from an eight-week mindfulness-based stress reduction course (Singleton et al., 2014).

These studies are helping to deepen our understanding of the neurobiological processes at work, and the physical effects on brain structure from mindfulness. In the next section we turn to consider the research findings from workplace studies.

\section{Organizational research}

Clearly many of the research studies discussed so far, which include health-based settings, have benefits that also contribute to the workplace performance of individuals, and their organizations, such as improved attention, improved working memory and greater focus. When specifically examining workplace settings a review of the workplace research literature by Allen et al. (2015) found 27 workplace studies, although a third of these were in healthcare organizational settings. These studies provide further evidence for mindfulness. Good and Lyddy (2016) in their own review identified a continued growth in the number of organization studies, but that in many areas the concluded the jury was still out as to the contribution of mindfulness. Mindfulnet.org cites a significantly higher number of studies that offer workplace benefits, summarized in Table 1.

Table 1: Organizational related mindfulness studies

\begin{tabular}{|l|l|}
\hline Mindfulness to factors that improve employee wellbeing & 58 studies \\
\hline Mindfulness to factors that improve leadership capability & 46 studies \\
\hline Mindfulness to factors that improve employee performance & 38 studies \\
\hline $\begin{array}{l}\text { Mindfulness to factors that impact on change and } \\
\text { organisational transformation }\end{array}$ & 34 studies \\
\hline $\begin{array}{l}\text { Mindfulness to factors that improve safety in high reliability } \\
\text { organisations }\end{array}$ & 33 studies \\
\hline
\end{tabular}

(Source: Mindfulnet.org, 2016)

For this paper we have decided to cluster the studies into three areas: personal performance related research, inter-personal relationships and health, wellbeing and employee turnover. This choice was made reflecting one way to cluster the data, and reflects common themes from our experience of working with organizational clients. 
For all organizations, the decision to draw on specific interventions, or invest in training, is driven by the perceived return on investment. Such returns are often difficult to measure, leading some to estimate the impact (Phillips, 2003) and others to focus on easier to measure variables, such as behavioural change or employee satisfaction (Passmore \& Velez, 2015). If mindfulness is going to truly take off as an organizational intervention beyond the area of wellbeing, it must provide clear evidence that it contributes to improvements in job performance. There is some evidence to show promising results. In a US restaurant environment, the researchers explored the relationship between workplace mindfulness and job performance $(n=98)$. They found that employees who received higher rates using an adapted version of the Mindfulness Attention Awareness Scale (MAAS) delivered higher levels of job performance, based on a manager rating. They concluded that even when allowing for experience and workplace factors, individuals who were more mindful at work, delivered higher performance (Dane \& Brummel, 2013). In a parallel study also using MAAS with a larger sample $(n=231)$ the researchers noted a positive relationship between higher manager ratings and higher levels of individual mindfulness (Reb, Narayanan \& Chaturvedi, 2014). Research by Spence (2008) found that clients who received mindfulness training, prior to starting cognitive behavioural solution focused coaching, experienced higher levels of goal directed self-regulation than the control group. While this was not directly related to job performance, a relationship between goal-directed behaviour and goal attainment has been found in other domains such as sport (Smith, 2016). As a result an argument may be made that as a result through enhancing goal directed behaviour, goal attainment (performance) will be enhanced. However alternative studies have been less conclusive. In a study of university employees $(n=94)$ using a diary methodology the researchers found only a weak association between mindfulness levels and work engagement (Tuckey et al., 2017). Clearly, more work is needed to explore to explore the relationship between mindfulness and individual performance.

A second area where mindfulness may make a useful contribution is inter-personal relationships and team performance. In a two-part study, Neff and her colleagues (Neff, Hsieh \& Dejitterat, 2005) explored the goal of self-compassion and its interaction with goal performance and attainment. In the first study $(n=222)$ they found that self-compassion was positively associated with mastery goals and negatively associated with performance goals. In the second part of the study $(n=110)$ they found self-compassion was positively associated with emotion-focused coping strategies such as the use of compassionate based mindfulness meditation.

This bodes well for managers seeking to enhance team performance, as work by Alimo-Metcalfe and Alban-Metcalfe (2001) has demonstrated more managers with higher levels of empathy are likely to be judged to be better leaders by their team. In another two part study using both diary $(n=219)$ and experimental design $(n=64)$ a team of researchers explored the contribution of mindfulness to emotional regulation and employee satisfaction. The research team found the participants who received mindfulness training reported lower levels of emotional exhaustion and higher levels of job satisfaction than those in the control group (Hülsheger et al., 
2013). In a review for the UK Government (The Mindfulness Initiative, 2016) the researchers claim a growing number of studies show the roll mindfulness practice may play in building organizational relationships (Glomb, et al., 2011)

These studies are far from conclusive evidence that mindfulness practice contributes to higher performance, but the evidence is beginning to hint that mindfulness may contribute in some areas to higher performance. Further research is needed using a range of measures before we are able to confirm the hypothesis that mindfulness practice is a useful tool to aid workplace performance.

The third area is that of health and wellbeing, an area where this is already good health evidence. From an employer perspective, the question may be reframed around whether mindfulness training or other mindfulness interventions can help reduce work related stress, and thus directly lead to reductions in absenteeism and employee turnover.

In the study conducted by Foureur, a mix of midwives and nurses $(n=40)$ participated in a one-day skills workshop and undertook to meditate daily for 8 weeks. They completed a pre and post intervention measures that included general health questionnaire (GHQ-12), sense of coherence (SOC), orientation to life and the depression, anxiety and stress scale (DASS). The researchers found significant improvements on the GHQ-12, SOC and the stress subscale of the DASS for the mindfulness group when compared with the control group.

Other studies looking at workplace stress directly have found similar positive findings. In a review of a series of nursing studies (Smith, 2012) examined the application of the eight-week MBSR programme with nurses. The researchers noted positive effects on stress reduction and reduced anxiety across a wide number of studies (Kang et al., 2009; Pipe et al., 2009; Beddoe \& Murphy, 2004; Rosenzweig et al., 2003; Shapiro et al., 1998, 2005, 2007). However what these studies have so far failed to do is measure the impact on the key organizational metrics of concern to HR managers; absenteeism and employee turnover. Is this topic however worthy of research attention?

A study (Reb, et al, 2013) examined attitudes of 231 employees. The researchers concluded that mindfulness was beneficially associated with employee wellbeing, as measured by emotional exhaustion, job satisfaction, and psychological need satisfaction, and was also associated with positive job performance, as measured by task performance, organizational citizenship behaviours.

A study by Chu (2010) suggested that this should be the focus of a future study. In a two part study firstly collected data from a large sample of working adults $(n=351)$ and secondly using an experimental design measured the effect on their emotional state $(n-20)$. The results indicated that those in the mindfulness intervention experienced improved emotional states when compared with the control using a pre and post evaluation measure (Chu, 2010). Once again while the study cannot conclude mindfulness interventions cause lower levels of absenteeism or reduce

Passmore, J. (2018). Mindfulness at organisations: A critical literature review. Industrial \& 9 Commercial Training. DOI: 10.1108/ICT-07-2018-0063 
turnover, we might hypothesis, based on this finding, a positive relationship will exist between the frequency of mindfulness practice and absenteeism levels. A clear link between the two will require further research, a large sample size, with random allocation of participants in the same industry and longitudinal data. Only through such a study can stress related absence be isolated from other common factors, such as back related injuries and the common cold, and the variations of these between industries, such as between nursing and IT sector workers.

In reviewing the evidence, it may be able to conclude that mindfulness might impact at four levels of what it is to be human: physiological, emotional, cognition, behavioural.

\section{Implications for research and practice}

Mindfulness research focused on health outcomes has shown that the intervention has significant positive effects when working with patients with a range of conditions. However, both the scale and scope of research into mindfulness within organisational settings means greater caution needs to be displayed when considering its potential as an intervention for employees. While there has been an explosion in the number of published papers since 2010, the relatively small number of quantitative studies compared with health means while the signs are positive, greater collaborative research is needed. Many of theses published organisational studies, have been conceptual papers, qualitative or preferred an experimental design, to the more complex randomised control trials. These studies have tended to be with a smaller sample sizes. While we can try to generalise from some of the health findings to organisational contexts, caution also needs to be taken. As a result wider, deeper and more robust research is required before we have evidenced to support mindfulness training as a ubiquitous intervention to deliver performance improvement or employee satisfaction.

Further, as with most interventions, the research has tended to focus on positive effects. We believe there also needs to be greater consideration of the risk facts associated with the application of mindfulness in organisational settings. For example, Glomb, et al. (2011) has suggested that while the intervention may enhance creativity (a helpful benefit in some areas of work) for more mundane tasks it may slow down employee performance. We would go further to speculate that mindfulness may also raise employee self-awareness, situational awareness and thus contribute to employee turnover, as employees leave for better employment prospects or seek more fulfilling and meaningful work. Further work research in this area is needed to ensure the application of mindfulness in organisational and employee development is evidenced based and targeted to bets effect, rather than being a panacea for all. 


\section{Conclusion}

In this paper we have briefly reviewed the evidence for mindfulness, as both an intervention for wellbeing, but also as a tool for organizations in search of improvements in performance, and employee satisfaction at a time when organizations are facing disruption for technology and wider economic factors. Our conclusion is that while the evidence is promising for its use as a tool, and there is strong evidence for improvements in well being, more research work is still needed to better understand the role mindfulness can play in individual performance, team climate and wider organizational performance., Organizations and academics need to engage in more collaboration research that provides studies with larger sample sizes, uses random allocation of participants between different conditions and adopts robust analysis of the data which is published whatever the result, allowing both negative outcomes and positive outcomes to be observed. 


\section{References}

Allen, T. D., Eby, L. T., Conley, K., Williamson, R., Mancini, V., \& Mitchell, M. E. (2015). What do we really know about the effects of mindfulness based training in the workplace. Industrial and Organizational Psychology, 8(4), 652-661. doi.org/10.1017/iop.2015.95

Alimo-Metcalfe, B. \& Alban-Metcalfe, J. (2001). The development of a new Transformational Leadership Questionnaire. Journal of Occupational \& Organizational Psychology, 74, 1-27.

AIS (2016, May 16). Workplace Stress. Retrieved from http://www.stress.org/workplace-stress/.

Barnes, S., Brown, K. W., Krusemark, E., Campbell, W. K., \& Rogge, R. D. (2007). The role of mindfulness in romantic relationship satisfaction and responses to relationship stress. Journal of Marital and Family Therapy, 33, 482-500. doi:10.1111/j.1752-0606.2007.00033.x

Beddoe, A., \& Murphy, S. (2004). Does mindfulness decrease stress and foster empathy among nursing students? Journal of Nursing Education, 43(7), 305-312.

Bhikkhu, B. (1998). Mindfulness with Breathing: A Manual for Serious Beginners. Somerville, MA: Wisdom Press.

Bishop, S. R., Lau, M., Shapiro, S., Carlson, L., Anderson, N., Carmody, J., Segal, Z., Abbey, S. Speca, M., Velting, D., \& Devins, G. (2004) Clinical Psychology: Science \& Practice, 11(3), 230-241.

Chambers, R., Lo, B. C. Y., \& Allen, N. B. (2008). The impact of intensive mindfulness training on attentional control, cognitive style, and affect. Cognitive Therapy and Research, 32, 303-322. doi:10.1007/s10608-007-9119-0.

Chaskalson, M. (2011). The Mindful Workplace: Developing resilient individuals and resonant organizations with MBSR. Chichester: Wiley.

Cropley, M., \& Purvis, L. J. (2003). Job strain and rumination about work issues during leisure time: A diary study. European Journal of Work and Organisational Psychology, 12, 195-207.

Chu, L. (2010). The benefits of meditation vis-à-vis emotional intelligence, perceived stress and negative mental health. Stress \& Health, 26(2), 169-180. doi:

10.1002/smi.1289.

Csikszentmihalyi, M. (1990). Flow: The Psychology of Optimal Experience. London: Random House. 
Cramer, H., Lauche, R., Paul, A., \& Dobos, G. (2012). Mindfulness based stress reduction for breast cancer - a systematic review and meta-analysis. Current Oncology, 19(5), 343-352. doi: 10.3747/co.19.1016.

Creswell, J. D., Taren, A. A., Lindsay, E. K., Greco, C.M., Gianaros, P. J., Fairgrieve, A., Marsland, A. L., \& Brown, K. W. (2016). Alterations in Resting-State Functional Connectivity Link Mindfulness Meditation With Reduced Interleukin-6: A Randomized Controlled Trial. Biological Psychiatry, 80, 53-61.

Dane, E., \& Brummel, B. J. (2014). Examining workplace mindfulness and its relations to job performance and turnover intention. Human Relations, 67(1), 105-128.

De Jong, Jong M., Lazar S. W., Hug K, Mehling . E., Hölzel B. K., Sack A. T., Peeters F., Ashih H., Mischoulon D. \& Gard T. (2016) Effects of Mindfulness-Based Cognitive Therapy on Body Awareness in Patients with Chronic Pain and Comorbid Depression Frontiers in Psychology, 7 967-982. DOI.10.3389/fpsyg.2016.00967

Dekeyser, M., Raes, F., Leijssen, M. Leyson, S., \& Dewulf, D. (2008). Mindfulness skills and interpersonal behavior. Personality and Individual Differences, 44, 1235-1245. doi:10.1016/j.paid.2007.11.018.

Dust, S. (2015). Mindfulness, Flow, and Mind Wandering: The Role of Trait-Based Mindfulness in State-Task Alignment. Industrial and Organizational Psychology 8(4), 1-6.

Foureur, M., Besley, K., Burton. G., Yu, N., \& Crisp. J. (2013). Enhancing the resilience of nurses and midwives: pilot of a mindfulness-based program for increased health, sense of coherence and decreased depression, anxiety and stress. Contemporary Nursing, 45(1), 114-125.

Glomb, T. M., Dufffy, M., Bono, J. E., \& Yang, T. (2011) Mindfulness at Work. In A. Joshi, H. Liao \& J. J. Martocchio (Eds.) Research in Personnel and Human Resources Management - Research in Personnel and Human Resources Management, Volume $30,115-157$.

Good, D., Lyddy. C., Glomb, T., Bono, J., Brown, K., Duffy, M., Baer, R., Brewer, J. \& Lazer, D., (2016) Comtemplating Mindfulness at Work: An integrative Review. Journal of Management. 42(1) 114 142. DOI: 10.1177/0149206315617003

Health \& Safety Executive. (2007). Health and Safety Statistics 2006/07. London: Health and Safety Executive.

Hofmann, S. G., Sawyer, A. T., Witt, A. A., \& Oh, D. (2010). The Effect of MindfulnessBased Therapy on Anxiety and Depression: A Meta-Analytic Review. Journal of Consulting Clinical Psychology, 78(2), 1690-183. doi: 10.1037/a0018555 
Hülsheger, U. R., Alberts, H. J. E. M., Feinholdt, A., \& Lang, J. W. B. (2013). Benefits of mindfulness at work: The role of mindfulness in emotion regulation, emotional exhaustion, and job satisfaction. Journal of Applied Psychology, 98(2), 310-325. http://dx.doi.org/10.1037/a0031313

Hyland, P., Lee, A., \& Mills, M. (2015). Mindfulness at Work: A New Approach to Improving Individual and Organizational Performance. Industrial \& Organizational Psychology: Perspective on Science and Practice, 8(4), 576-602.

Jha, A. P., Stanley, E. A., Kiyonaga, A., Wong, L., \& Gelfand, L. (2010). Examining the protective effects of mindfulness training on working memory capacity and affective experience. Emotion, 10, 54-64.

Kabat-Zinn, J. (1991), Full catastrophe living: using the wisdom of your body and mind to face stress, pain, and illness, New York: Delta Trade Paperbacks.

Kang, Y., Choi, S., \& Ryu, E. (2009). The effectiveness of a stress coping program based on mindfulness meditation on the stress, anxiety, and depression experienced by nursing students in Korea. Nurse Education Today, 29(5), 538-543. doi:10.1016/j.nedt.2008.12.003

Kelly, C. (2012, April 28). O.K., Google, Take a Deep Breath. New York Times.

Lutz, A., Jha, A. P., Dunne, J. D., \& Saron, C. D. (2015). Investigating the phenomenological matrix of mindfulness-related practice from a neurocognitive perspective. American Psychologist, 70 (7), 632-658.

McCraty, R. M., Barrios-Choplin, B., Rozman, D., Atkinson, M. \& Watkins, A. D. (1998). The impact of a new emotional self-management program on stress, emotions, heart rate variability, DHEA and cortisol. Integrative Psychological and Behavioural Science, 33 (2), 151-170.

Mindfulnet (2016) Gathering the evidence base for mindfulness at work: scientifically evaluated and academic research (2016). Retrieved on 8 November 2018 from http://www.mindfulnet.org/page18.htm

Moore, A., \& Malinowski, P. (2009). Meditation, mindfulness and cognitive flexibility. Consciousness and Cognition, 18, 176-186.

Neff, K. D., Hsieh, Y. P., \& Dejitterat, K. (2005). Self-compassion, achievement goals, and coping with academic failure. Self and Identity, 4, 263-287.

Reb, J., Narayanan, J. \& Ho, Z. W. (2013). Mindfulness at work: Antecedents and Consequences of employee awareness and absent-mindedness. Mindfulness, 6(1), 111-122.

Neubauer, A. C., \& Fink, A. 2009. Intelligence and neural efficiency. Neuroscience and Biobehavioral Reviews, 33: 1004-1023.

Passmore, J. (2018). Mindfulness at organisations: A critical literature review. Industrial \& 14 Commercial Training. DOI: 10.1108/ICT-07-2018-0063 
Ocasio, W. 2011. Attention to attention. Organization Science, 22: 1286-1296.

Ortner, C, N. M., Kilner, S. J., \& Zelazo, P. D. (2007). Mindfulness meditation and reduced emotional interference on a cognitive task. Motivation and Emotion, 31(4), 271-283.

Parswarni, M. J., Sharma, M. P., \& lyengar, S. S. (2013). Mindfulness based stress reduction in coronary heart disease: A randomised control trail. International Journal of Yoga, 6(2), 111-117. doi:10.4103/0973-6131.113405.

Passmore, J. \& Velez, M. (2015). Training Evaluation. In K. Kraiger, J. Passmore, N. dos Santos \& S. Malvezzi The Wiley Blackwell Handbook of the Psychology of Training, Development \& Performance Improvement (pp136-153). Chichester: Wiley Blackwell.

Phillips, J. J. (2003). Return on Investment in Training and Performance Improvement Programs (Improving Human Performance). London: Routledge.

Pipe, T., Bortz, J., Dueck, A., Pendergast, D., Buchda, V., \& Summers, J. (2009). Nurse leader mindfulness meditation program for stress management: A randomized controlled trial. Journal of Nursing Administration, 39(3), 130-137.

doi:10.1097/NNA.0b013e31819894a0

Purser, R., \& Loy, D., (2013, July 1). Beyond McMindfulness. The Huffington Post. Retrieved from http://www.huffingtonpost.com/ron-purser/beyond-mcmindfulness b 3519289.html

Rein, G., \& McCraty, R. M. (1995). Effects of positive and negative emotions on salivary IgA. Journal for the Advancement of Medicine, 8 (2), 87-105.

Reb, J., Narayanan, J., \& Ho, Z. W. 2015. Mindfulness at work: Antecedents and consequences of employee awareness and absent-mindedness. Mindfulness, 6: 111122.

Rosenzweig, S., Reibel, D., Greeson, J., Brainard, G., \& Hojat, M. (2003). Mindfulnessbased stress reduction lowers psychological distress in medical students. Teaching and Learning in Medicine, 15(2), 88-92.

Shapiro, S., Schwartz, G., \& Bonner, G. (1998). Effects of mindfulness-based stress reduction on medical and premedical students. Journal of Behavioral Medicine, 21(6), 581-599.

Smallwood, J., \& Schooler, J. W. (2006). The restless mind. Psychological Bulletin, 132, 946-958. doi: 10.1037/0033-2909.132.6.946

Smallwood, J., \& Schooler, J. W. 2015. The science of mind wandering: Empirically

Passmore, J. (2018). Mindfulness at organisations: A critical literature review. Industrial \& 15 Commercial Training. DOI: 10.1108/ICT-07-2018-0063 
navigating the stream of consciousness. Annual Review of Psychology, 66: 487-518.

Shapiro, S. L., Astin, J. A., Bishop, S. R., \& Cordova, M. (2005). Mindfulness-based stress reduction for health care professionals: Results from a randomized trial. International Journal of Stress Management, 12(2), 164-176.

Shapiro, S., Brown, K., \& Biegel, G. (2007). Teaching self-care to caregivers: Effects of mindfulness-based stress reduction on the mental health of therapists in training. Training and Education in Professional Psychology, 1(2), 105-115. doi:10.1037/19313918.1.2.105

Singleton O., Hölzel B. K., Vangel M., Brach N., Carmody J., \& Lazar SW. (2014). Change in brainstem gray matter concentration following a mindfulness-based intervention is correlated with improvement in psychological wellbeing. Frontiers in human neuroscience. 8(33). doi: 10.3389/fnhum.2014.00033.

Spence, G. (2008). New directions in evidence-based coaching: investigations into the impact of mindfulness training goal attainment and wellbeing. Saarbrucken, Germany: VDM.

Smith, S. A. (2014). Mindfulness based stress reduction. International Journal of Nursing Knowledge, 25(2), 119-130.

Smith, A. (2016). Coach Behaviors and Goal Motives as Predictors of Attainment and Well-Being in Sport. In A. Rabb et al. Sport and Exercise Psychology Research , pp 415-432.

Taren, A., Creswell, J. D., \& Gianaros, P. (2013). Dispositional Mindfulness Co-Varies with Smaller Amygdala and Caudate Volumes in Community Adults. PLOS One, doi: 10.1371/journal.pone.0064574

The Mindfulness Initiative (2016). Building the case for Mindfulness in the workplace. Private Sector Working Group. London: Mindfulness Initiative

Thomsen, D. K. (2004) The association between rumination and negative effect: A Review. Cognition and Emotion, 20(8), 1216-1235.

Tuckey, M. R., Sonnentag, S. \& Bryant, J. (2017) Are state mindfulness and state work engagement related during the workday? Work and Stress: An International journal of work, health and organizations, 32(1), 33-48.

doi:10.1080/02678373.2017.1420707

Wachs, K., \& Cordova, J. V. (2007). Mindful relating: Exploring mindfulness and emotion repertoires in intimate relationships. Journal of Marital and Family Therapy, 33, 464-481. doi:10.1111/j.1752-0606.2007.00032.x

Wolever, R. Q., Bobinet, K. J., McCabe, K., Mackenzie, E. R., Fekete, E., Kusnick, C A., \& Baime, M. (2012). Effective and viable mind-body stress reduction in the

Passmore, J. (2018). Mindfulness at organisations: A critical literature review. Industrial \& 16 Commercial Training. DOI: 10.1108/ICT-07-2018-0063 
workplace: A randomized controlled trial. Journal of Occupational Health Psychology, 17(2), 246-258. doi:10.1037/a0027278

Yeganeh, B. (2006). Mindful Experiential Learning. PhD Thesis, Case Western Reserve University, Department of Organizational Behavior. 